\title{
Erratum to: Chronic Paroxetine Treatment Prevents the Emergence of Abnormal Electroencephalogram Oscillations in Huntington's Disease Mice
}

\author{
Sandor Kantor $^{1} \cdot \operatorname{Janos}_{\operatorname{Varga}^{1}} \cdot$ Shreya Kulkarni $^{1}$ • A. Jennifer Morton ${ }^{1}$
}

Published online: 25 July 2017

(C) The American Society for Experimental NeuroTherapeutics, Inc. 2017

Erratum to: Neurotherapeutics

DOI 10.1007/s13311-017-0546-7

The original article has been corrected to make the spelling of electroencephalogram consistent throughout this article and to fix spacing between words in the legend to Figure 6.

The online version of the original article can be found at http://dx.doi.org/ 10.1007/s13311-017-0546-7.

A. Jennifer Morton ajm41@cam.ac.uk

1 Department of Physiology, Development and Neuroscience,

University of Cambridge, Cambridge, UK 